\title{
Siponimod and Cognition in Secondary Progressive Multiple Sclerosis EXPAND Secondary Analyses
}

Ralph H.B. Benedict, PhD, Davorka Tomic, MD, Bruce A. Cree, MD, Robert Fox, MD, Gavin Giovannoni, MD, Amit Bar-Or, MD, Ralf Gold, MD, Patrick Vermersch, MD, Harald Pohlmann, MSc, lan Wright, PhD, Göril Karlsson, MD, Frank Dahlke, MD, Christian Wolf, MD, and Ludwig Kappos, MD

Neurology ${ }^{\circledR}$ 2021;96:e376-e386. doi:10.1212/WNL.0000000000011275

\section{Abstract}

\section{Objective}

To investigate the effects of siponimod on cognitive processing speed in patients with secondary progressive (SP) multiple sclerosis (MS), by means of a predefined exploratory and post hoc analysis of the Exploring the Efficacy and Safety of Siponimod in Patients With Secondary Progressive Multiple Sclerosis (EXPAND) study, a randomized controlled trial comparing siponimod and placebo.

\section{Methods}

EXPAND was a double-blind, placebo-controlled phase 3 trial involving 1,651 patients with SPMS randomized $(2: 1)$ to either siponimod $2 \mathrm{mg} / \mathrm{d}$ or placebo. Cognitive function was assessed with the Symbol Digit Modalities Test (SDMT), Paced Auditory Serial Addition Test (PASAT), and Brief Visuospatial Memory Test-Revised (BVMT-R) administered at baseline, 6-month intervals, and end of treatment.

\section{Results}

Between-group differences in mean change from baseline in SDMT scores were significantly better in siponimod- vs placebo-treated patients at month 12 (difference 1.08 [95\% confidence interval 0.23-1.94]; $p=0.0132)$, month 18 (1.23 [0.25-2.21); $p=0.0135)$, and month $24(2.30$ [1.11-3.50]; $p=0.0002)$. Siponimod-treated patients were at significantly lower risk for having a 4-point sustained decrease in SDMT score (hazard ratio [HR] 0.79 [0.65-0.96]; $p=0.0157$ ), while their chance for having a 4-point sustained increase in SDMT score was higher (HR 1.28 [1.05-1.55]; $p=0.0131)$. PASAT and BVMT-R scores did not differ significantly between the 2 treatment groups (all $p>0.28)$.

\section{Conclusion}

Siponimod had a significant benefit on SDMT in patients with SPMS. Siponimod-treated patients were at significantly lower risk for having a $\geq 4$-point decrease in SDMT score and had a significantly higher chance for having a $\geq 4$-point increase in SDMT score, a magnitude of change accepted as clinically meaningful.

\section{ClinicalTrials.gov Identifier \\ NCT01665144.}

\section{Classification of Evidence}

This study provides Class II evidence that, for patients with SPMS, siponimod had a significant benefit on cognitive processing speed.

\author{
Correspondence \\ Dr. Benedict \\ benedict@buffalo.edu
}

\section{RELATED ARTICLE}

\section{Editorial}

Siponimod for Cognition in Secondary Progressive Multiple Sclerosis: Thinking Through the Evidence

Page 91

\section{MORE ONLINE}

\section{$\rightarrow$ Class of Evidence}

Criteria for rating therapeutic and diagnostic studies

NPub.org/coe

From the Department of Neurology (R.H.B.B.), University at Buffalo, NY; Novartis Pharma AG (D.T., H.P., G.K., F.D.), Basel, Switzerland; Weill Institute for Neurosciences (B.A.C.), Department of Neurology, University of California San Francisco; Mellen Center for Treatment and Research in Multiple Sclerosis (R.F.), Neurological Institute, Cleveland Clinic, OH; Blizard Institute (GG), Barts and The London School of Medicine and Dentistry, Queen Mary University of London, UK; Department of Neurology (A.B.-O.), Perelman School of Medicine, University of Pennsylvania, Philadelphia; Department of Neurology (R.G.), St. Josef-Hospital/Ruhr-University Bochum, Germany; Department of Neurology (P.V.), University of Lille, INSERM U1172, CHU Lille, FHU Imminent, France; Novartis Ireland Ltd (I.W.), Dublin; Lycalis sprl (C.W.), Brussels, Belgium; and Neurologic Clinic and Policlinic (G.K., L.K.), Departments of Medicine, Clinical Research, Biomedicine, and Biomedical Engineering, University Hospital and University of Basel, Switzerland.

Go to Neurology.org/N for full disclosures. Funding information and disclosures deemed relevant by the authors, if any, are provided at the end of the article. 


\section{Glossary}

ASCEND = A Clinical Study of the Efficacy of Natalizumab on Reducing Disability Progression in Participants With Secondary Progressive Multiple Sclerosis; BVMT-R = Brief Visuospatial Memory Test-Revised; CDP = confirmed disability progression; CI = confidence interval; CPS = cognitive processing speed; DECIDE = Efficacy and Safety of BIIB019 (Daclizumab High Yield Process) Versus Interferon $\beta$ 1a in Participants With Relapsing-Remitting Multiple Sclerosis; EDSS = Expanded Disability Status Scale; EXPAND = Exploring the Efficacy and Safety of Siponimod in Patients With Secondary Progressive Multiple Sclerosis; Gd = gadolinium; HR = hazard ratio; IFN- $\beta$-1a = interferon beta-1a; MS = multiple sclerosis; MSOAC = Multiple Sclerosis Outcome Assessments Consortium; OPERA = A Study of Ocrelizumab in Comparison With Interferon Beta-1a (Rebif) in Participants With Relapsing Multiple Sclerosis; PASAT = Paced Auditory Serial Addition Test; SDMT = Symbol Digit Modalities Test; S1P = sphingosine-1-phosphate; SPMS = secondary progressive MS.

Multiple sclerosis (MS) is an immune-mediated neurodegenerative disease affecting cognitive function, particularly among those with progressive course. ${ }^{1,2}$ MS neurocognitive disorder affects driving, adherence to medication regimens, employment, computer-based purchasing, and rehabilitation potential. ${ }^{3,4}$ The core deficit lies in the domain of cognitive processing speed $(\mathrm{CPS})^{5}$ with carryover effects to higherorder cognitive processes. ${ }^{6-8}$ Consensus opinion considers the Symbol Digit Modalities Test (SDMT) the best measure of CPS for MS studies. ${ }^{9}$ It is the only CPS test for which a change score is defined as clinically meaningful. ${ }^{10}$

Siponimod is a modulator of sphingosine-1-phosphate (S1P) receptor function with specificity for the S1P1 and S1P5 subtypes of the S1P receptor. ${ }^{11}$ It readily crosses the blood-brain barrier $^{12}$ and may have direct actions in the CNS that limit inflammation and promote remyelination. ${ }^{13-15}$ In Exploring the Efficacy and Safety of Siponimod in Patients With Secondary Progressive Multiple Sclerosis (EXPAND), a multicenter, randomized, double-blind, parallel-group, placebo-controlled phase 3 trial, siponimod significantly reduced confirmed disability progression (CDP) in progressive MS compared with placebo. ${ }^{16}$

Here, our objectives are to report results from the prespecified exploratory analyses of between-group differences in change from baseline at months 12 and 24 and averaged over all visits for the cognitive tests used in the EXPAND study and the post hoc responder analyses for SDMT outcomes applying an accepted threshold for clinically meaningful change. ${ }^{10}$ We present data in the overall population and in subgroups defined by their pretreatment characteristics for disease activity, disability status, and CPS impairment.

\section{Methods}

\section{Primary Research Question}

Does siponimod improve CPS compared with placebo in patients with secondary progressive (SP) MS?

\section{Standard Protocol Approvals, Registrations, and Patient Consents}

This trial is registered with ClinicalTrials.gov (NCT01665144). The trial protocol was approved by the independent ethics committee at each trial center. All patients provided written informed consent. The trial adhered to the International Conference on Harmonization Guidelines for Good Clinical Practice and to the Declaration of Helsinki. Institutional review boards or ethics committees approved the protocol at all sites. All patients included in the analysis gave written informed consent before starting the study. The study was funded by Novartis Pharma AG.

\section{Study Design and Participants}

EXPAND was a randomized, double-blind, placebo-controlled, event- and exposure-driven clinical trial to investigate the efficacy, safety, and tolerability of siponimod in patients with SPMS. Study design and results for the EXPAND study were reported. ${ }^{16}$ In brief, 1,651 patients with SPMS were randomized (2:1) to receive either siponimod $2 \mathrm{mg} / \mathrm{d}$ or placebo in the doubleblind part of the study. The double-blind part of the study was stopped once a predefined number of disability progression events were observed and after $>95 \%$ of randomized patients were randomized for at least 1 year. During the trial, patients with established disease progression could switch to open-label siponimod as rescue medication or go off treatment (either with or without another disease-modifying therapy); 94 patients in the placebo group (17.2\%) and 116 patients in the siponimod group (10.6\%) switched to open-label siponimod, while 135 and 57 patients, respectively, went off treatment.

Eligibility criteria were age of 18 to 60 years, diagnosis of SPMS, ${ }^{17,18}$ progression on the Expanded Disability Status Scale (EDSS) in the prior 2 years, and an EDSS score of 3.0 to 6.5 at screening. Unlike most neuropsychological studies in MS, patients in the EXPAND study were not prescreened and excluded for factors known to affect the development of cognitive abilities such a childhood learning disability and neurologic and psychiatric disorders such as traumatic brain injury and bipolar disorder. Thus, the study is representative of the general advanced MS population but is also susceptible to potential biases introduced by including participants with these factors.

The primary objective of EXPAND was to evaluate the efficacy of siponimod relative to placebo in delaying the time to 3 -month CDP as measured by the EDSS. Three-month CDP was defined as an increase from baseline EDSS score subsequently confirmed after at least 3 months. The study 
Table 1 Baseline Characteristics

\begin{tabular}{|c|c|c|c|}
\hline Characteristic & Siponimod $(n=1,105)$ & Placebo $(n=546)$ & Total $(n=1,651)$ \\
\hline Age, y & $48.0(7.8)$ & $48.1(7.9)$ & $48.0(7.9)$ \\
\hline Age $>40 \mathrm{y}, \mathrm{n}(\%)$ & $917(83.0)$ & $443(81.1)$ & $1,360(82.4)$ \\
\hline Female sex, $\mathrm{n}(\%)$ & $669(60.5)$ & $323(59.2)$ & $992(60.1)$ \\
\hline Time since diagnosis of MS, y & $12.9(7.9)$ & $12.1(7.5)$ & $12.6(7.8)$ \\
\hline Time since onset of MS symptoms, y & $17.1(8.4)$ & $16.2(8.2)$ & $16.8(8.3)$ \\
\hline Time since conversion to SPMS, y & $3.9(3.6)$ & $3.6(3.3)$ & $3.8(3.5)$ \\
\hline Time since onset of last relapse, $y$ & $5.1(5.1)$ & $4.5(4.6)$ & $4.9(4.9)$ \\
\hline No relapses in year before screening, $n(\%)$ & $878(79.5)$ & $416(76.2)$ & $1,294(78.4)$ \\
\hline No relapses in 2 y before screening, $n$ (\%) & $712(64.4)$ & $343(62.8)$ & $1,055(63.9)$ \\
\hline EDSS score, median & 6.0 & 6.0 & 6.0 \\
\hline EDSS score $\geq 6, n(\%)$ & $622(56.3)$ & $296(54.2)$ & $918(55.6)$ \\
\hline SDMT raw score ${ }^{a}$ & $38.9(13.9)$ & $39.6(13.3)$ & $39.1(13.8)$ \\
\hline Median (minimum-maximum) & $40.0(0.0-83.0)$ & $42.0(0.0-83.0)$ & $41.0(0.0-83.0)$ \\
\hline Baseline SDMT score $<43^{e}, n(\%)$ & $616(55.7)$ & $283(51.8)$ & $899(54.5)$ \\
\hline PASAT raw score ${ }^{b}$ & $39.2(14.5)$ & $38.9(14.4)$ & $39.1(14.5)$ \\
\hline Median (minimum-maximum) & $42.0(0.0-60.0)$ & $41.0(0.0-60.0)$ & $42.0(0.0-60.0)$ \\
\hline BVMT-R Total Recall score ${ }^{c}$ & $20.6(8.8)$ & $20.4(8.9)$ & $20.5(8.9)$ \\
\hline Median (minimum-maximum) & $21.0(0.0-36.0)$ & $21.0(0.0-36.0)$ & $21.0(0.0-36.0)$ \\
\hline BVMT-R Delayed Recall score ${ }^{d}$ & $8.1(3.4)$ & $8.0(3.4)$ & $8.1(3.4)$ \\
\hline Median (minimum-maximum) & $9.0(0.0-22.0)$ & $9.0(0.0-10.0)$ & $9.0(0.0-22.0)$ \\
\hline
\end{tabular}

Abbreviations: BVMT-R = Brief Visuospatial Memory Test-Revised; EDSS = Expanded Disability Status Scale; MS: multiple sclerosis; PASAT = Paced Auditory Serial Addition Test; SDMT = Symbol Digit Modalities Test; SPMS = secondary progressive multiple sclerosis.

Data are presented as mean (SD) unless otherwise indicated.

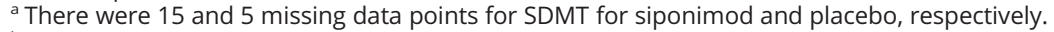

${ }^{\mathrm{b}}$ There were 23 missing data points for PASAT for siponimod.

' There were 27 and 12 missing data points for BVMT-R for siponimod and placebo, respectively.

${ }^{\mathrm{d}}$ There were 36 and 21 missing data points for BVMT-R for siponimod and placebo, respectively.

e Impairment being defined as a baseline SDMT score $<43$ points, i.e. $\geq 2$ SD below the mean of healthy population normal.

showed a benefit of siponimod with an estimated hazard ratio (HR) of 0.79 (95\% confidence interval [CI] 0.65-0.95), i.e., a relative risk reduction of $21 \%$.

MRI scans were performed every 12 months. For the purposes of this report, MRI was used to identify acute disease activity defined by gadolinium (Gd) enhancement at each time point. The data were analyzed independently at a central reading site (NeuroRX Research, Montreal, Quebec, Canada) by staff unaware of trial treatment group assignments.

\section{Cognitive Assessments}

Cognitive outcomes included the SDMT (score range 0-110, higher score indicates better performance), ${ }^{19}$ Paced Auditory Serial Addition Test (PASAT; score range 0-60, higher score indicates better performance), ${ }^{20,21}$ and the Brief Visuospatial Memory Test-Revised (BVMT-R; score range 0-36, higher score indicates better performance). ${ }^{22}$ While the SDMT is regarded as the most sensitive of neurocognitive tests in MS research, ${ }^{1,2,10}$ the PASAT and BVMT-R are also widely accepted measures of working memory and episodic memory, respectively. ${ }^{23-25}$

The tests were administered at baseline, at 6-month intervals after randomization, and at the end of treatment or end of the core part of the study. To minimize practice effects, the original SDMT and 2 alternative forms shown to be equivalent in difficulty were presented in an alternating pattern. ${ }^{26}$ Throughout the study, only the oral response administration of the SDMT was used. Likewise, 2 PASAT forms (A and B) were used in alternating order $(\mathrm{A}, \mathrm{B}, \mathrm{A}$, etc) in each successive visit. The BVMT-R has 6 validated, equivalent, alternative forms, and the total learning score (sum of trials 1, 2, and 3) was recorded for the sole BVMT-R outcome measure, as per 
Figure 1 Mean Change from Baseline in SDMT Score

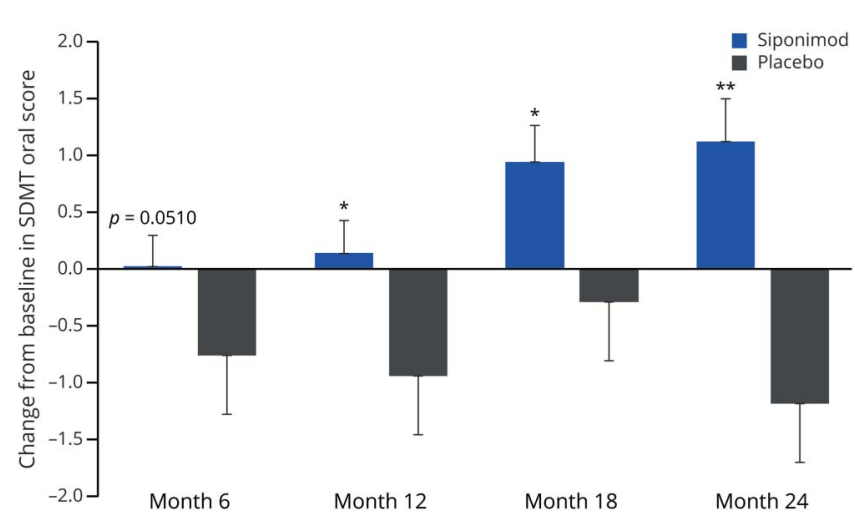

Mean change from baseline in Symbol Digit Modalities Test (SDMT) score at months $6,12,18$, and 24 . Error bars represent the standard error. ${ }^{\star} p<0.05$ $\star \star p<0.01$.

Brief International Cognitive Assessment for Multiple Sclerosis guidelines. $^{24}$

\section{Statistical Analyses}

The full analysis set, comprising all randomized and treated patients, was used for the primary and post hoc analyses. Patients were analyzed according to the randomized treatment assignment following the intention-to-treat principle, using all available assessments of the core part, regardless of the actual study treatment received. As with the analysis of the primary EXPAND outcome (3-month CDP), the full analysis set was used to determine efficacy on cognition because this approach is recommended by International Conference on Harmonization guidance. $^{27}$

Summary statistics were generated for each visit at which cognitive functions were tested. Between-group differences in change from baseline were analyzed using mixed-model repeated-measures methodology with visit as a categorical factor and adjustment for treatment and baseline score. These differences were evaluated at months 6, 12, 18, and 24 .

Increase (i.e., improvement) or decrease (i.e., worsening) in SDMT score by 4 points is accepted as a clinically meaningful change. ${ }^{10}$ Cox regression analysis was used to provide analyses based on clinical meaningful change, i.e., the time to sustained 4-point decrease and time to sustained 4-point increase in SDMT score. Sustained change was defined as a change from baseline that continued until the end of followup in the core part without ever returning above or below this threshold. Results are presented as HRs, which provide the ratio of risk (or chance) for sustained deterioration (improvement) between siponimod and placebo.

With the same Cox regression approach, homogeneity of results over subgroups was evaluated. The subgroup results are presented in a forest plot, showing the HRs of the subgroup categories in relation to the $\mathrm{HR}$ of the overall population. Presenting estimates in forest plots is an appropriate method for comparing homogeneity of subgroups, for which $p$ value-based analyses are less meaningful due to multiplicity and small sample size issues.

Cox regression analyses for sustained worsening and sustained improvement were done for the following subgroups: (1) patients characterized by the presence or absence of CPS impairment before entering the EXPAND study with impairment being defined as a baseline SDMT of $<43$ points, i.e., $\geq 2$ SD below the mean of healthy population norms ${ }^{28}$; (2) patients with Gd-enhancing/positive or Gd-negative lesions; (3) patients with relapsing SPMS and nonrelapsing SPMS; and (4) SDMT-measured CPS changes in patients in EXPAND with an EDSS score $<6$ (fully ambulatory) vs patients with an EDSS score $\geq 6$ (using ambulatory support) before entering the EXPAND study.

Numbers needed to treat were calculated for the risk (or chance) for sustained 4-point decreases or increases based on the HRs derived from the Cox proportional hazards models.

\section{Data Availability}

The data for the analyses described in this article are available by request from the authors or Novartis Pharma AG.

\section{Results}

\section{Baseline Characteristics}

Patient characteristics in the 2 treatment arms were similar (table 1$)$. The majority of patients (63.9\%) had not had any relapses within 2 years before screening. A majority of patients (55.6\%) had an EDSS score $\geq 6$ (i.e., used a walking aid before study entry). Almost half of the patients (46.7\%) had an impaired prestudy SDMT score.

The core part of the study was completed by $81.7 \%$ of patients in the siponimod group and $77.7 \%$ of patients in the placebo group. Median duration of patient participation in the core phase (on double-blind treatment, on open-label siponimod as rescue medication, or off treatment) was 21 months (range $0.2-37$ months). The median duration of exposure to randomized double-blind study drug was 18 months (range $0-37$ months). Further details are available in the primary publication. ${ }^{16}$ As a result of the flexible-duration study design, in which patients entered the study sequentially over a long period but completed the study at the same point in time, the number of patients with assessments available decreases substantially over time. In addition, exposure to double-blind study medication could be discontinued after reaching 6-month CDP.

\section{Changes in CPS as Measured by SDMT}

Change in SDMT score between baseline and month 12 was evaluable in 1,365 patients and between baseline and month 
Figure 2 Participants Evidencing a Sustained Deterioration or Improvement (Both $\geq 4$ Points) in SDMT Score

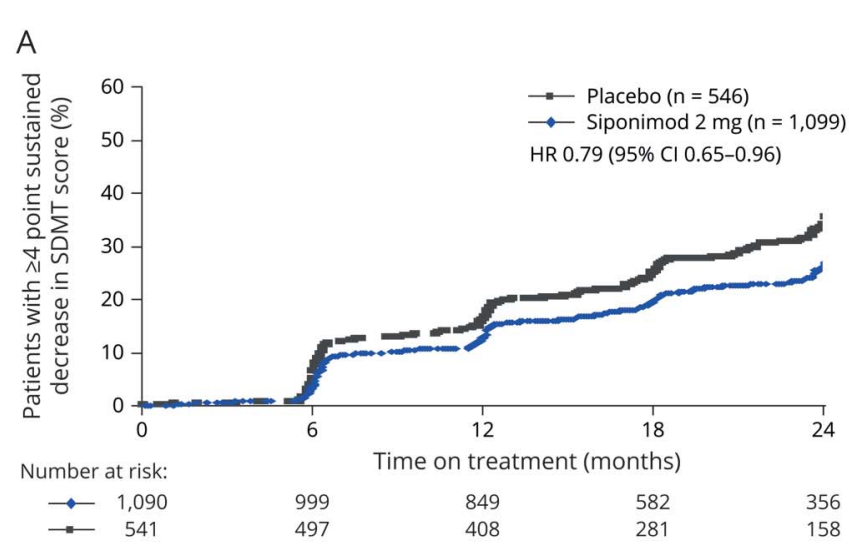

$\mathrm{B}$

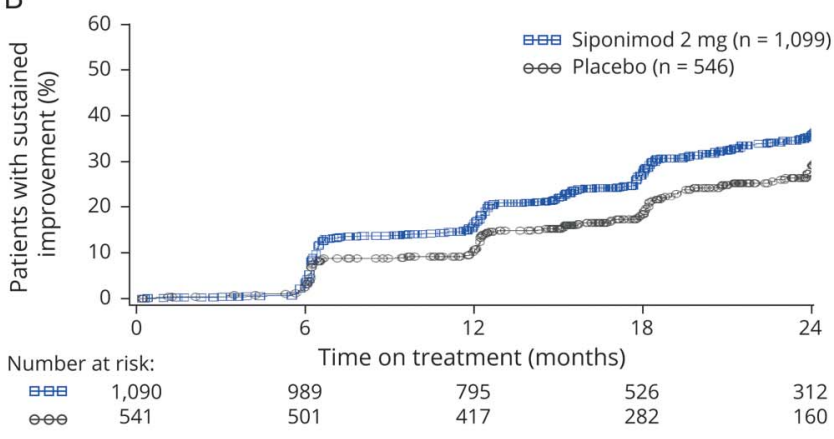

C

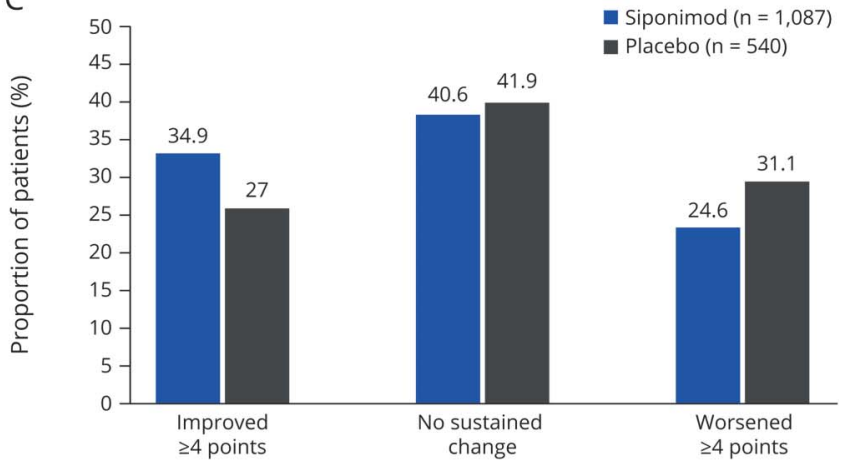

(A) Kaplan-Meier analysis of the percentage of participants evidencing a sustained deterioration in the Symbol Digit Modalities Test (SDMT) score by $\geq 4$ points. Hazard ratio (HR) 0.79 (95\% confidence interval $[\mathrm{Cl}] 0.65-0.96), p=$ 0.0157 . (B) Kaplan-Meier analysis of the percentage of patients over time who had a sustained improvement in SDMT score by $\geq 4$ points. HR 1.28 (95\% Cl 1.05-1.55), $p=0.0131$. (C) Cox regression analysis of the proportion of participants improving and worsening is statistically significant ( $p=0.0131)$. Graph contrasts proportions in siponimod (blue) against placebo (gray), with change in SDMT score defined by 4 points. ${ }^{10}$

24 in 445 patients. Time to sustained changes in SDMT score was evaluable in 1,627 patients. Missing SDMT scores are mostly a result of the variable duration of patient participation.

The mixed-model repeated-measures model showed that between-group differences in mean change from baseline in SDMT scores were significantly better in siponimod-treated patients compared with placebo-treated patients at months 12,18 , and 24 (figure 1).

\section{Clinically Meaningful Changes in SDMT Score}

Patients in the siponimod group were at significantly lower risk for having a 4-point sustained decrease in SDMT score (figure 2A), while their chance for having a 4-point sustained increase in SDMT score was significantly higher (figure 2B). The Kaplan-Meier graph showed that this difference in risk was already evident at month 6 (the first postrandomization time at which it was evaluated) and continued throughout the course of double-blind treatment (figure 2A).

Cox regression analysis found that the chance for sustained improvement by $\geq 4$ points was increased by $27.5 \%$ in the siponimod group compared with the placebo group $(p=0.0131)$. The proportions of patients who had a sustained improvement in SDMT score by $\geq 4$ points, a sustained deterioration in SDMT score by $\geq 4$ points, or no sustained changes of a magnitude of $\geq 4$ points (no sustained change) are shown in figure $2 \mathrm{C}$.

A number needed to treat analysis found that 32 patients need to be treated with siponimod over 12 months to prevent 1 additional event of sustained deterioration (decrease by $\geq 4$ points) in SDMT, while 17 patients need to be treated over 24 months to prevent 1 additional event of sustained deterioration in SDMT. When 37 patients are treated with placebo instead of siponimod over 12 months, there is 1 fewer patient with sustained improvement (increase by $\geq 4$ points) in SDMT score, while 16 patients need to be treated with placebo over 24 months for 1 fewer patient with sustained improvement.

\section{Subgroup Analyses}

For all analyzed subgroups, the proportion of patients with sustained improvement in SDMT was higher for siponimod vs placebo, while the proportion of patients with sustained deterioration was lower with siponimod vs placebo. Likewise, chances to improve and risks to deteriorate favored siponimod over placebo in all subgroups (figure 3). The HRs in the subgroup analysis were relatively similar between subgroup categories and similar to the HR in the overall population.

In patients with or without cognitive impairment at baseline, the proportion of patients with sustained improvement in SDMT score was higher for siponimod vs placebo, reaching significance for those without impairment (HR 1.49 [95\% CI $1.09-2.04] ; p=0.0126$ ), while the proportion of patients with sustained deterioration was lower with siponimod vs placebo, reaching significance for patients with or without cognitive impairment (HR 0.72 [0.53-0.96], $p=0.0269$; and HR 0.76 [0.58-1.00]; $p=0.0477$, respectively).

In patients with or without Gd-positive lesions at baseline, the proportion of patients with sustained deterioration was lower with siponimod vs placebo, reaching significance for patients with Gd-positive lesions (HR 0.56 [0.36-0.87]; $p=0.0093$ ).

In patients with relapsing SPMS and nonrelapsing SPMS, the proportion of patients with sustained improvement in SDMT was higher for siponimod vs placebo, reaching 


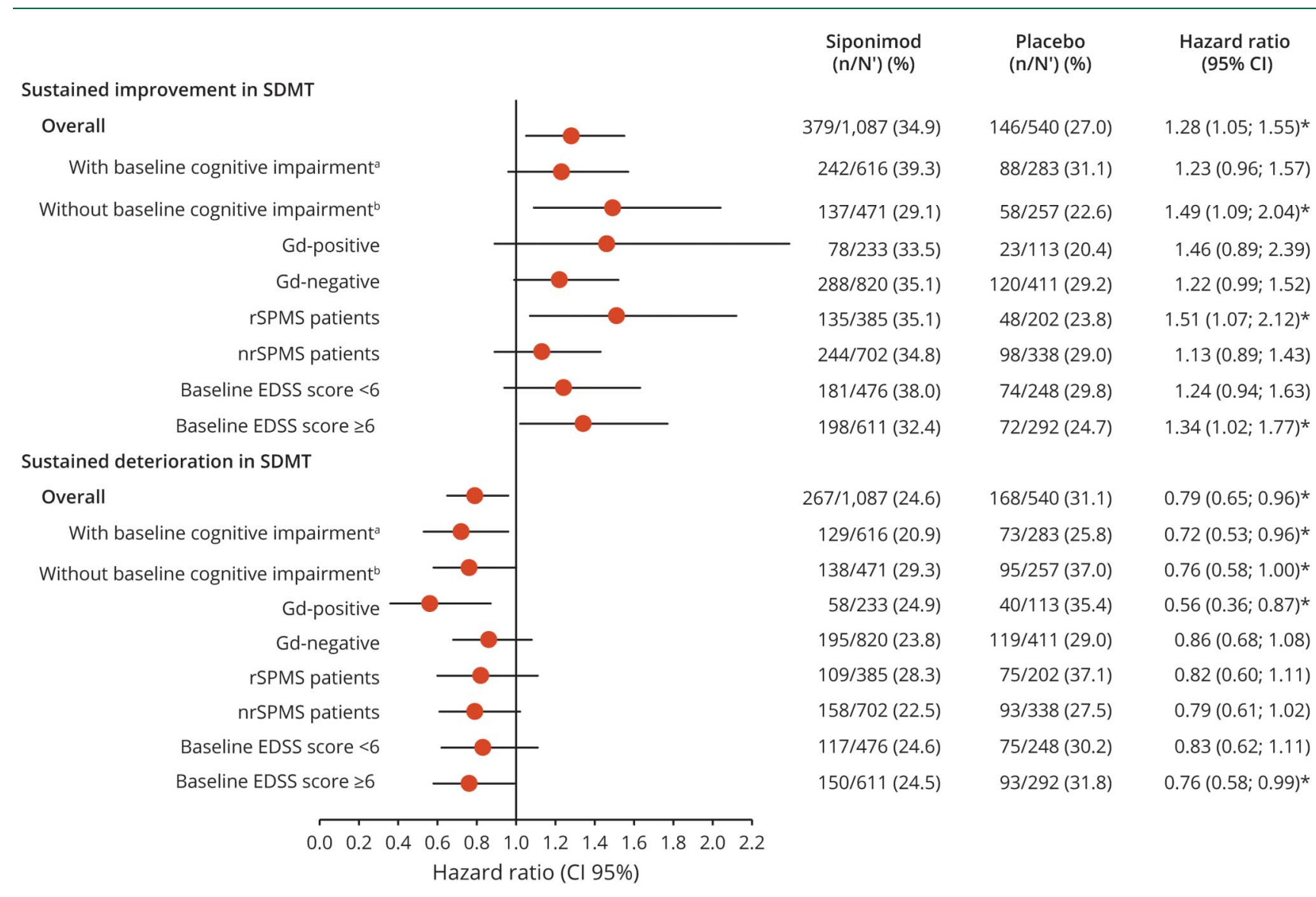

Symbol Digit Modalities Test (SDMT) subgroup analyses for sustained changes. For improvement, a hazard ratio (HR) >1.0 favors siponimod; for deterioration, an HR <1.0 favors siponimod. Cox proportional hazards model was used with treatment, country, baseline Expanded Disability Status Scale (EDSS) score, baseline SDMT-Oral score, and secondary progressive multiple sclerosis (SPMS) group (with/without superimposed relapses, baseline definition) as covariate. $\mathrm{Cl}=$ confidence interval; $\mathrm{Gd}$ = gadolinium; $\mathrm{n} / \mathrm{N}^{\prime}$ = number of participants with sustained improvement or deterioration/number of participants included in the analysis (i.e., with nonmissing covariates); nrSPMS, nonrelapsing SPMS; rSPMS, relapsing SPMS. * $p<0.05$. ${ }^{\mathrm{a} B a s e l i n e ~ S D M T ~ s c o r e ~<43 ; ~}{ }^{\mathrm{b}}$ baseline SDMT score $\geq 43$.

significance for patients with relapsing SPMS (HR 1.51 [1.07-2.12]; $p=0.0176)$.

In patients with a baseline EDSS score $<6$ and in those with baseline EDSS score $\geq 6$ before entering the EXPAND study, the proportion of patients with sustained improvement in SDMT was higher for siponimod vs placebo, reaching significance in those with EDSS score $\geq 6$ (HR 1.34 [1.02-1.77]; $p=0.0358$ ), while the proportion of patients with sustained deterioration was lower with siponimod vs placebo, again reaching significance in those with EDSS score $\geq 6$ (HR 0.76 [0.58-0.99]; $p=0.0437)$.

\section{Other Cognitive Outcomes}

Change in PASAT score between baseline and month 12 was evaluable in 1,337 patients and between baseline and month 24 in 580 patients. Changes in BVMT-R Total Recall and Delayed Recall scores between baseline and month 12 were evaluable in 1,347 and 1,332 patients, respectively, and between baseline and month 24 in 588 and 582 patients, respectively.
PASAT and BVMT-R scores did not differ significantly between the 2 treatment groups (table 2). There were no significant effects or trends toward significance in these analyses (all $p>0.28$ ).

\section{Adverse Events}

As previously reported, ${ }^{16}$ the safety and tolerability of siponimod in the EXPAND study were comparable to those of other drugs in the S1P-receptor modular class. Adverse events more frequent in patients on siponimod than in patients on placebo included elevated liver transaminase concentrations, bradycardia at treatment initiation, macular edema, hypertension, varicella zoster virus reactivation, and convulsions, all of which have been described previously for other drugs of the class. Frequencies of infections, malignancies, or death were not increased.

\section{Discussion}

These phase 3 data from the EXPAND study provide Class II evidence that patients with SPMS treated with siponimod 
Table 2 Change from Baseline in PASAT and BVMT-R Scores in the Full Analysis Set

\begin{tabular}{|c|c|c|c|c|}
\hline & \multicolumn{2}{|c|}{ Adjusted Means (SE) } & \multirow[b]{2}{*}{ Between-Group Difference $(95 \% \mathrm{Cl})$} & \multirow[b]{2}{*}{$p$ Value } \\
\hline & Siponimod & Placebo & & \\
\hline PASAT, $\mathbf{n}$ & 1,011 & \multicolumn{3}{|l|}{509} \\
\hline Month 12 & $2.25(0.300)$ & $1.80(0.427)$ & $0.45(-0.57$ to 1.47$)$ & 0.3869 \\
\hline Month 24 & $2.98(0.404)$ & $2.38(0.579)$ & $0.59(-0.79$ to 1.98$)$ & 0.4015 \\
\hline Average over all visits ${ }^{a}$ & $2.30(0.269)$ & $1.83(0.382)$ & $0.48(-0.44$ to 1.39$)$ & 0.3088 \\
\hline BVMT-R, Total Recall score, $n$ & 1,011 & \multicolumn{3}{|l|}{508} \\
\hline Month 12 & $0.21(0.223)$ & $0.56(0.298)$ & $-0.35(-1.01$ to 0.32$)$ & 0.3070 \\
\hline Month 24 & $1.78(0.319)$ & $1.33(0.452)$ & $0.45(-0.59$ to 1.49$)$ & 0.3944 \\
\hline Average over all visits $^{a}$ & $0.67(0.225)$ & $0.57(0.309)$ & $0.11(-0.58$ to 0.79$)$ & 0.7605 \\
\hline BVMT-R, delayed recall, $\mathrm{n}$ & 1,003 & \multicolumn{3}{|l|}{498} \\
\hline Month 12 & $-0.11(0.090)$ & $0.04(0.121)$ & $-0.15(-0.42$ to 0.12$)$ & 0.2844 \\
\hline Month 24 & $0.44(0.134)$ & $0.43(0.190)$ & $0.01(-0.43$ to 0.45$)$ & 0.9641 \\
\hline Average over all visits $^{a}$ & $0.08(0.090)$ & $0.10(0.124)$ & $-0.01(-0.29$ to 0.26$)$ & 0.9198 \\
\hline \multicolumn{5}{|c|}{$\begin{array}{l}\text { Abbreviations: BVMT-R = Brief Visuospatial Memory Test-Revised; } \mathrm{Cl}=\text { confidence interval; } \mathrm{SE}=\text { standard error; PASAT = Paced Auditory Serial Addition Test. } \\
\text { Between-group differences in change from baseline were analyzed using mixed-model repeated-measures methodology with visit as a categorical factor and } \\
\text { adjustment for treatment and baseline score. Adjusted mean (SE) refers to the change from baseline in PASAT score or to the change from baseline in Total/ } \\
\text { Delayed Recall score. } \\
\text { a Includes all post-baseline visits through month } 30 \text {. Statistical significance ( } 2 \text { sided) at the } 0.05 \text { level was used. }\end{array}$} \\
\hline
\end{tabular}

experience significant improvement on the SDMT. Preplanned analyses of between-group differences significantly favored siponimod over placebo. Post hoc responder analyses suggest that these effects are clinically meaningful, ${ }^{10}$ because siponimod-treated patients were also at significantly lower risk for having a $\geq 4$-point decrease in SDMT score and had a significantly higher chance for having a $\geq 4$-point increase in SDMT score. Indeed, the $21 \%$ risk reduction with siponimod in the proportion of patients with a 4-point sustained worsening in SDMT score reported here is in line with the 25\% risk reduction reported for 6-month confirmed 4-point worsening in SDMT score. ${ }^{29}$

While patients with less advanced disease (those without baseline cognitive impairment [SDMT score $\geq 43]$ ) appear to have a higher chance for sustained improvement in SDMT with siponimod vs placebo, patients with more advanced disease (those with baseline cognitive impairment [SDMT score $<43$ ]) appear to have a lower risk for sustained worsening with siponimod vs placebo. A possible explanation for this is that patients with more acute disease activity and less cognitive impairment may still have cognitive (i.e., neurologic) reserve available to turn the benefit of siponimod on CPS into improvement, while in later-stage, more impaired patients, the benefit may be a slowing of further decline, although it is also possible that this might simply be a floor effect. It is also feasible that it might take longer than the median treatment duration of 18 months for treatment effect to be observed in later-stage and more-impaired patients. Studies of patients treated with siponimod for longer duration are needed.
The EXPAND extension study is still ongoing and may deliver such information.

The benefit from siponimod was restricted to cognitive function as measured by the SDMT. Both SDMT and PASAT are used to assess cognitive function in $\mathrm{MS}^{30-35}$ although PASAT is more susceptible to practice effects ${ }^{9,36,37}$ and is found by patients to be stressful. ${ }^{36}$ SDMT as an accepted marker for clinically meaningful difference, ${ }^{10}$ is less prone to measurement error, ${ }^{28}$ and has high reliability and sensitivity. ${ }^{38}$ Correlations between SDMT and job loss ${ }^{39}$ and fluctuations in clinical status during relapse ${ }^{40-42}$ are well known. Including SDMT as a measure for CPS in EXPAND overcomes earlier shortfalls in most MS phase 3 studies to capture a wider spectrum of functional deficits (the Efficacy and Safety of BIIB019 [Daclizumab High Yield Process] Versus Interferon $\beta$ 1a in Participants With RelapsingRemitting Multiple Sclerosis [DECIDE] study $^{33}$ is an exception). Past characterizations of functional deficits often used only the physically focused EDSS alone or the PASAT with the above-described shortcomings. The threshold approach used for the analysis of SDMT data was based on the consensus perspective of the Multiple Sclerosis Outcome Assessments Consortium (MSOAC). ${ }^{43-45}$ Neuropsychological studies have shown that 4-point changes in SDMT are often associated with clinically meaningful alterations in mental status. ${ }^{10}$ Recent studies validate this threshold as being associated with quality of life outcomes ${ }^{5}$ and progression of MS disability. ${ }^{7,46}$ 
We are impressed with the results showing an effect of siponimod on SDMT, without any evidence of benefit on the PASAT or BVMT-R. As noted by others, ${ }^{1,10}$ the SDMT is sensitive, but it is not specific to the CPS domain. SDMT involves paired-associate learning and visual scanning, so the more demanding the task is, the more likely it is that it will measure the effects of cerebral pathology in general. This may explain in part the value of the SDMT in clinical and research applications as noted in a recent consensus report organized by the MSOAC. ${ }^{10}$ In further support, ${ }^{47}$ lesion-based white matter tract disruptions were shown to be much more extensively involved across left and right hemisphere networks compared with the BVMT-R. Moreover, siponimod has shown, ex vivo, partial restoration of cortical neuronal circuit function, ${ }^{48}$ together with a reduction in cortical gray matter and thalamic volume loss, in patients with SPMS, ${ }^{49}$ which correlated with the SDMT score. Volume of the thalamus, a hub for multiple neural networks, ${ }^{50}$ is robustly correlated with SDMT in both cross-sectional ${ }^{51}$ and longitudinal studies ${ }^{52}$ of MS. As mentioned, PASAT is more susceptible to practice effects $^{9,36,37}$ and thus may be a less sensitive measure during the core study. The neuroprotective effect of siponimod by partially restoring cortical neuronal circuit after crossing the blood-brain barrier would appear to be independent of its peripheral effects on immune cells. ${ }^{48}$

BVMT-R is also a gold standard neuropsychological assessment in MS but instead examines new learning and episodic memory. ${ }^{23,24,53,54}$ According to published norms, ${ }^{55} 44 \%$ of patients had impaired BVMT-R Total Recall score and $48 \%$ of patients had impaired BVMT-R Delayed Recall score at baseline, similar to the rate of impairment in CPS based on the SDMT score. Since the early work published on the effects of interferon beta-1a (IFN- $\beta$-1a), ${ }^{56}$ no disease-modifying therapy has shown a statistically significant effect on memory in a phase 3 trial. SDMT may be more sensitive to the effects of disease-modifying therapy because it involves multiple neural networks ${ }^{57}$ compared to BVMT-R, for example. ${ }^{47}$ SDMT performance can be related to visual/spatial processing and ocular motor functions, and it involves some incidental learning of symbol-digit associations.

EXPAND included a typical SPMS population. Fifty-six percent of patients needed walking aids; nearly two-thirds had no relapses in the 2 years before study entry. Only $\approx 20 \%$ of patients had focal inflammatory brain activity at baseline. ${ }^{16}$ Across SPMS trials, both EXPAND ${ }^{16}$ and A Clinical Study of the Efficacy of Natalizumab on Reducing Disability Progression in Participants With Secondary Progressive Multiple Sclerosis (ASCEND) study of the effects of natalizumab ${ }^{58}$ enrolled a high proportion of severely disabled patients. Compared with other studies in progressive MS, EXPAND recruited patients with similar or longer mean and median times since onset of progression. In this population with established physical disabilities and baseline SDMT scores well below average, significant benefit on SDMT was observed.
In relapsing-remitting MS, a beneficial effect was found in ocrelizumab-treated patients vs IFN- $\beta$ - 1 a on SDMT score in A Study of Ocrelizumab in Comparison With Interferon Beta1a (Rebif) in Participants With Relapsing Multiple Sclerosis (OPERA) I and OPERA II. ${ }^{59}$ A full report of these data awaits publication, but the main article describes a greater increase in SDMT score from baseline favoring ocrelizumab over IFN$\beta$-1a at week $96(p=0.023)$. The only other detailed post hoc analysis of SDMT phase 3 data is found among patients with relapsing-remitting MS in the DECIDE study of daclizumab vs IFN- $\beta-1 \mathrm{a} .{ }^{33}$ In this investigation, the same form of SDMT was administered every 3 months. Significantly greater mean improvement from baseline in SDMT score was observed for daclizumab, and more patients treated with daclizumab had a 24-point increase, suggesting a clinically meaningful benefit. In general, it would appear that the effects of diseasemodifying therapies on MS include benefits for cognition, as measured within the CPS domain, using the SDMT in particular. Of these recent phase 3 trials, only EXPAND included a test of memory. It remains to be seen whether the lack of impact on memory reported here is unique to this intervention or if the effects of disease-modifying therapies in MS are less impactful in cognitive spheres other than CPS.

The behavior of the comparator arm in this study is noteworthy, revealing no substantial improvement. Again, considering this result in the context of the DECIDE and OPERA studies, ${ }^{33,59}$ we note that in EXPAND alternative forms of the SDMT were used to minimize learning effects on the outcome measure. In contrast, the same number/symbol combinations were repeated throughout the OPERA and DECIDE studies. ${ }^{33,59}$ The lack of improvement in our study may reflect better control of learning effects. In addition, the improvement in SDMT in the IFN- $\beta$-1a-treated comparator arms of DECIDE and OPERA observed previously may partly reflect the effects of IFN- $\beta$-1a over and above that of placebo or a less advanced relapsing MS population.

There were several limitations. While the analyses of betweengroup differences for change from baseline at months 12 and 24, for SDMT, PASAT, and BVMT-R were prespecified in the protocol, responder analyses and analyses for sustained changes were planned and done post hoc; the study was designed after consensus on a clinically meaningful difference was derived by the MSOAC. ${ }^{43}$ Another limitation is that we did not collect demographic data such as education or common MS symptoms such as visual impairment, fatigue, and depression because the primary outcome in the phase 3 trial was neurologic disability. Considering the randomization used, it is unlikely that these variables differed across the treatment groups, but these factors may nevertheless have moderated the impact of siponimod on cognition. Education, a proxy for cognitive, influences SDMT performance, ${ }^{60}$ as does depression. ${ }^{61}$ The time-to-event study design leading to variable duration of study participation and the protocolendorsed switch to open-label siponimod for patients with established progression of disability encumbered comparisons 
for the protocol-defined time points. Although only $\approx 20 \%$ (18.3\% randomized to siponimod, $22.3 \%$ randomized to placebo) of patients discontinued the study prematurely, at later time points, the number of available assessments was substantially reduced due to the flexible study duration per patient. This leads to greater CIs in the treatment effect estimates, but potential bias, usually introduced by dropout related to study treatment, is limited because most of the missing assessments are due to the study design and are not related to study treatment. Comparing the number needed to treat values reveals that the effect size in this study is modest, as is also appreciated in comparisons of the differences in group means at the 12- and 24-month time points. Finally, the findings in this study may not be applicable in populations of patients who differ from those enrolled in EXPAND, as evidenced by the low deterioration rate seen in the patients receiving placebo from the ASCEND study at 2 years.

The overall findings from this study in a population with advanced neurologic disability suggest that treatment with siponimod beneficially affects cognitive functioning as measured by the SDMT, a benefit likely to have a high impact on quality of life and vocational status. The benefits observed were seen in patients with or without prestudy relapses, in patients with or without cognitive impairment before study entry, and in patients with an EDSS score $\geq 6$ or $<6$. Benefits were observed in the time to sustained change until the end of follow-up in the core study. Treatment effects observed for clinical and imaging outcomes, most notably reduction in brain volume loss as an objective marker of permanent tissue damage and thus likely related to cognitive function, ${ }^{49}$ are consistent with the results reported here.

\section{Acknowledgment}

The authors acknowledge the support of Daniela Piani Meier (from Novartis). The authors also thank Farid Khalfi (from Novartis Ireland Ltd) for technical editing of the outline in accordance with Good Publication Practice (GPP3) guidelines (ismpp.org/gpp3). The final responsibility for the content lies with the authors.

\section{Study Funding}

The study was funded by Novartis Pharma AG, Basel, Switzerland.

\section{Disclosure}

R.H.B. Benedict reports research support and grants from the NIH, National MS Society, Biogen, Genzyme, Mallinkrodt, and Genentech. He has consulting or speaking relationships with EMD Serono, Biogen, Novartis, Sanofi, Genzyme, Verasci, and Roche, and he receives royalties from Psychological Assessment Resources, Inc. B. Cree has received personal compensation for consulting from AbbVie, Biogen Idec, EMD Serono, MedImmune, Novartis, Genzyme/Sanofi Aventis, and Teva Neurosciences. R. Fox has received compensation for serving as consultant or speaker from Allozyne,
Avanir, Biogen Idec, Novartis, Questcor, and Teva Pharmaceutical Industries. He or the institution he works for has received research support from Novartis. G. Giovannoni is a steering committee member on the daclizumab trials for AbbVie, the BG12 and daclizumab trials for Biogen-Idec, the fingolimod and siponimod trials for Novartis, the laquinimod trials for Teva, and the ocrelizumab trials for Roche. He has also received consultancy fees for advisory board meetings for oral cladribine trials for Merck-Serono and Genzyme-Sanofi and in relation to Data Safety Monitoring Board activities for Synthon BV, as well as honoraria for speaking at the physicians' summit and several medical education meetings. He is also the co-chief editor of Multiple Sclerosis and Related Disorders (Elsevier). A. Bar-Or has received personal compensation for consulting, serving on scientific advisory boards, and/or speaking activities from Bayer, Bayhill Therapeutics, Berlex, Biogen Idec, BioMS, Diogenix, Eli Lilly, F. HoffmannLa Roche Ltd, Genentech, GlaxoSmithKline (GSK), GuthyJackson/GGF, Merck Serono, Novartis, Ono Pharmacia, Sanofi-Aventis, Teva Neuroscience, and Wyeth. R. Gold has received compensation for serving as a consultant or speaker from Bayer HealthCare, Biogen Idec, Merck Serono, Novartis, and Teva Neuroscience, and he or the institution he works for has received research support from Bayer HealthCare, Biogen Idec, Merck Serono, Novartis, and Teva Neuroscience; he has also received honoraria as a journal editor from SAGE and Thieme Verlag. P. Vermersch has received honoraria and consulting fees from Biogen, Genzyme-Sanofi, Roche, Novartis, Merck, Celgene, MedDay, and Almirall, as well as research support from Biogen, Genzyme-Sanofi, Roche, and Merck. L. Kappos has received no personal compensation. Ludwig Kappos' institution (University Hospital Basel) has received in the last 3 years and used exclusively for research support the following: steering committee, advisory board, and consultancy fees from Actelion, Addex, Bayer HealthCare, Biogen Idec, Biotica, Genzyme, Lilly, Merck, Mitsubishi, Novartis, Ono Pharma, Pfizer, Receptos, Sanofi, Santhera, Siemens, Teva, UCB, and Xenoport; speaker fees from Bayer HealthCare, Biogen Idec, Merck, Novartis, Sanofi, and Teva; support of educational activities from Bayer HealthCare, Biogen, CSL Behring, Genzyme, Merck, Novartis, Sanofi, and Teva; license fees for Neurostatus products; and grants from Bayer HealthCare, Biogen Idec, European Union, Innoswiss, Merck, Novartis, Roche Research Foundation, Swiss MS Society, and the Swiss National Research Foundation. C. Wolf is a partner at Lycalis sprl and reports compensation for his organization for consulting from Novartis, Roche, Teva, Celgene, Mylan, Synthon, 2BBB, ICON, Immunic, and Desitin and for speaking from Mylan and Synthon. D. Tomic, H. Pohlmann, G. Karlsson, and F. Dahlke are employees of Novartis. I. Wright is a contractor with Novartis Ireland Ltd. Go to Neurology.org/ $\mathrm{N}$ for full disclosures.

\section{Publication History}

Received by Neurology October 28, 2019. Accepted in final form August 20, 2020. 
Appendix Authors

\begin{tabular}{|c|c|c|}
\hline Name & Location & Contribution \\
\hline $\begin{array}{l}\text { Ralph H.B. } \\
\text { Benedict, } \\
\text { PhD }\end{array}$ & $\begin{array}{l}\text { Department of Neurology, } \\
\text { University at Buffalo, NY }\end{array}$ & $\begin{array}{l}\text { Study design; interpretation } \\
\text { of data; intellectual content } \\
\text { and critical review of data; } \\
\text { major contribution for } \\
\text { authoring and revising } \\
\text { the manuscript }\end{array}$ \\
\hline
\end{tabular}

$\begin{array}{ll}\text { Davorka } & \text { Novartis Pharma AG, } \\ \text { Tomic, MD } & \text { Basel, Switzerland }\end{array}$

Interpretation of data; intellectual content and critical review of data; major contributions for authoring and revising the manuscript

\begin{tabular}{lll}
\hline $\begin{array}{l}\text { Bruce A. } \\
\text { Cree, MD }\end{array}$ & $\begin{array}{l}\text { UCSF Weill Institute for } \\
\text { Neurosciences, } \\
\text { Department of Neurology, } \\
\text { University of California San } \\
\text { Francisco }\end{array}$ & $\begin{array}{l}\text { Study design; interpretation } \\
\text { of data; intellectual content } \\
\text { and critical review of data; } \\
\text { revising and input into the } \\
\text { manuscript }\end{array}$ \\
\hline $\begin{array}{l}\text { Robert Fox, } \\
\text { MD }\end{array}$ & $\begin{array}{l}\text { Mellen Center for } \\
\text { Treatment and Research in } \\
\text { Multiple Sclerosis, } \\
\text { Neurologic Institute, } \\
\text { Cleveland Clinic, OH }\end{array}$ & $\begin{array}{l}\text { Study design; } \\
\text { interpretation of data; } \\
\text { intellectual content and } \\
\text { critical review of data; } \\
\text { revising and input into the } \\
\text { manuscript }\end{array}$ \\
& &
\end{tabular}

\begin{tabular}{lll}
\hline Gavin & Blizard Institute, Barts and & Study design; \\
Giovannoni, & The London School of & interpretation of data; \\
MD & Medicine and Dentistry, & intellectual content and \\
Queen Mary University of & $\begin{array}{l}\text { critical review of data; } \\
\text { revising and input into the } \\
\text { London, UK }\end{array}$ & manuscript
\end{tabular}

Amit Bar-Or Department of Neurology, Study design; interpretation $\begin{array}{ll}\text { Amit Bar-Or, } & \text { Department of Neurology, } \\ \text { MD } & \text { Perelman School of }\end{array}$ Medicine, University of Pennsylvania, Philadelphia

of data; intellectual content and critical review of data; revising and input into the manuscript

\begin{tabular}{ll}
\hline Ralf Gold, & Department of Neurology, \\
MD & St. Josef-Hospital/Ruhr- \\
& University Bochum, \\
& Germany
\end{tabular}

\section{Study design;}

interpretation of data; intellectual content and critical review of data; revising and input into the manuscript

\begin{tabular}{ll}
\hline Patrick & Department of Neurology, \\
Vermersch, & University of Lille, INSERM- \\
MD & U995, CHU Lille, FHU \\
& Imminent, France
\end{tabular}

\section{Study design;} interpretation of data; intellectual content and critical review of data; revising and input into the manuscript

\begin{tabular}{ll}
\hline Harald & Novartis Pharma AG, \\
Pohlmann, & Basel, Switzerland \\
MSc &
\end{tabular}

Study design; statistical analysis of the data; Interpretation of data; intellectual content and critical review of data; revising and input into the manuscript

\begin{tabular}{lll}
\hline $\begin{array}{l}\text { Ian Wright, } \\
\text { PhD }\end{array}$ & $\begin{array}{l}\text { Novartis Ireland Ltd, } \\
\text { Dublin, Ireland }\end{array}$ & $\begin{array}{l}\text { Medical writing support for } \\
\text { drafting and revision of } \\
\text { manuscript }\end{array}$ \\
\hline $\begin{array}{l}\text { Göril } \\
\text { Karlsson, } \\
\text { MD }\end{array}$ & $\begin{array}{l}\text { Novartis Pharma AG, } \\
\text { Basel, Switzerland }\end{array}$ & $\begin{array}{l}\text { Interpretation of data; } \\
\text { intellectual content and } \\
\text { critical review of data; } \\
\text { revising and input into } \\
\text { the manuscript }\end{array}$ \\
\hline $\begin{array}{l}\text { Frank } \\
\text { Dahlke, MD }\end{array}$ & Novartis Pharma AG, & $\begin{array}{l}\text { Interpretation of data; } \\
\text { intellectual content and } \\
\text { Basel, Switzerland } \\
\text { revising and input into the } \\
\text { manuscript }\end{array}$ \\
& &
\end{tabular}

Appendix (continued)

\begin{tabular}{|c|c|c|}
\hline Name & Location & Contribution \\
\hline $\begin{array}{l}\text { Christian } \\
\text { Wolf, MD }\end{array}$ & $\begin{array}{l}\text { Lycalis sprl, Brussels, } \\
\text { Belgium }\end{array}$ & $\begin{array}{l}\text { Interpretation of data; } \\
\text { intellectual content and } \\
\text { critical review of data; } \\
\text { major contributions for } \\
\text { authoring and revising the } \\
\text { manuscript }\end{array}$ \\
\hline $\begin{array}{l}\text { Ludwig } \\
\text { Kappos, MD }\end{array}$ & $\begin{array}{l}\text { Neurologic Clinic and } \\
\text { Policlinic, Departments of } \\
\text { Medicine, Clinical } \\
\text { Research, Biomedicine and } \\
\text { Biomedical Engineering, } \\
\text { University Hospital and } \\
\text { University of Basel, } \\
\text { Switzerland }\end{array}$ & $\begin{array}{l}\text { Study design; } \\
\text { interpretation of data; } \\
\text { intellectual content and } \\
\text { critical review of data; } \\
\text { revising and input into the } \\
\text { manuscript }\end{array}$ \\
\hline
\end{tabular}

\section{References}

1. Sumowski JF, Benedict R, Enzinger C, et al. Cognition in multiple sclerosis: state of the field and priorities for the future. Neurology 2018;90:278-288.

2. Benedict RHB, DeLuca J, Enzinger C, Geurts JJG, Krupp LB, Rao SM. Neuropsychology of multiple sclerosis: looking back and moving forward. J Int Neuropsychol Soc 2017;23:832-842.

3. Langdon DW. Cognition in multiple sclerosis. Curr Opin Neurol 2011;24:244-249.

4. Goverover Y, Chiaravalloti N, DeLuca J. Brief International Cognitive Assessment for Multiple Sclerosis (BICAMS) and performance of everyday life tasks: actual reality. Mult Scler 2016;22:544-550.

5. Costa SL, Genova HM, DeLuca J, Chiaravalloti ND. Information processing speed in multiple sclerosis: past, present, and future. Mult Scler 2017;23:772-789.

6. Forn C, Belenguer A, Parcet-Ibars MA, Avila C. Information-processing speed is the primary deficit underlying the poor performance of multiple sclerosis patients in the Paced Auditory Serial Addition Test (PASAT). J Clin Exp Neuropsychol 2008;30: 789-796.

7. Genova HM, DeLuca J, Chiaravalloti N, Wylie G. The relationship between executive functioning, processing speed, and white matter integrity in multiple sclerosis. J Clin Exp Neuropsychol 2013;35:631-641.

8. DeLuca J, Chelune GJ, Tulsky DS, Lengenfelder J, Chiaravalloti ND. Is speed of processing or working memory the primary information processing deficit in multiple sclerosis? J Clin Exp Neuropsychol 2004;26:550-562.

9. Strober L, DeLuca J, Benedict RH, et al. Symbol Digit Modalities Test: a valid clinical trial endpoint for measuring cognition in multiple sclerosis. Mult Scler 2019;25: 1781-1790.

10. Benedict RH, DeLuca J, Phillips G, et al. Validity of the Symbol Digit Modalities Test as a cognition performance outcome measure for multiple sclerosis. Mult Scler 2017; 23:721-733.

11. Gergely P, Nuesslein-Hildesheim B, Guerini D, et al. The selective sphingosine 1-phosphate receptor modulator BAF312 redirects lymphocyte distribution and has species-specific effects on heart rate. Br J Pharmacol 2012;167:1035-1047.

12. Aslanis V, Faller T, Van de Kerkhof E, Schubart A, Wallström E, Beyerbach A. Siponimod (BAF312) (and/or its metabolites) penetrates into the CNS and distributes to white matter areas. Mult Scler 2012;18(suppl):355-356.

13. Gentile A, Musella A, Bullitta S, et al. Siponimod (BAF312) prevents synaptic neurodegeneration in experimental multiple sclerosis. J Neuroinflammation 2016;13:207.

14. Jackson SJ, Giovannoni G, Baker D. Fingolimod modulates microglial activation to augment markers of remyelination. J Neuroinflammation 2011;8:76.

15. Mannioui A, Vauzanges Q, Fini JB, et al. The Xenopus tadpole: an in vivo model to screen drugs favoring remyelination. Mult Scler 2018;24:1421-1432.

16. Kappos L, Bar-Or A, Cree BAC, et al. Siponimod versus placebo in secondary progressive multiple sclerosis (EXPAND): a double-blind, randomised, phase 3 study. Lancet 2018;391:1263-1273.

17. Lublin FD, Reingold SC. Defining the clinical course of multiple sclerosis: results of an international survey: National Multiple Sclerosis Society (USA) advisory committee on clinical trials of new agents in multiple sclerosis. Neurology 1996;46:907-911.

18. Rovaris M, Confavreux C, Furlan R, Kappos L, Comi G, Filippi M. Secondary progressive multiple sclerosis: current knowledge and future challenges. Lancet Neurol 2006;5:343-354.

19. Smith A. Symbol Digit Modalities Test: Manual. Los Angeles: Western Psychological Services; 1982.

20. Fischer JS, Rudick RA, Cutter GR, Reingold SC. The Multiple Sclerosis Functional Composite Measure (MSFC): an integrated approach to MS clinical outcome assessment: National MS Society Clinical Outcomes Assessment Task Force. Mult Scler 1999;5:244-250.

21. Gronwall DM. Paced auditory serial-addition task: a measure of recovery from concussion. Percept Mot Skills 1977;44:367-373. 
22. Benedict RHB, Schretlen S, Groninger L, Dobraski M, Shpritz B. Revision of the brief visuospatial memory test: studies of normal performance, reliability, and validity. Psychol Assess 1996;8:145-153.

23. Erlanger DM, Kaushik T, Caruso LS, et al. Reliability of a cognitive endpoint for use in a multiple sclerosis pharmaceutical trial. J Neurol Sci 2014;340:123-129.

24. Langdon DW, Amato MP, Boringa J, et al. Recommendations for a Brief International Cognitive Assessment for Multiple Sclerosis (BICAMS). Mult Scler 2012;18:891-898.

25. Benedict RHB, Fischer JS, Archibald CJ, et al. Minimal neuropsychological assessment of MS patients: a consensus approach. Clin Neuropsychol 2002;16:381-397.

26. Benedict RH, Smerbeck A, Parikh R, Rodgers J, Cadavid D, Erlanger D. Reliability and equivalence of alternate forms for the Symbol Digit Modalities Test: implications for multiple sclerosis clinical trials. Mult Scler 2012;18:1320-1325.

27. European Medicines Agency. Guidance Issuing Office. Statistical Principles for Clinical Trials: E9. London: ICH; 1998.

28. Drake AS, Weinstock-Guttman B, Morrow SA, Hojnacki D, Munschauer FE, Benedict $\mathrm{RH}$. Psychometrics and normative data for the multiple sclerosis functional composite: replacing the PASAT with the Symbol Digit Modalities Test. Mult Scler 2010; 16:228-237.

29. Mayzent. Summary of Product Characteristics. European Medicines Agency. Available at: https://www.ema.europa.eu/en/documents/product-information/mayzentepar-product-information_en.pdf. Accessed December 14, 2020.

30. Riccitelli GC, Pagani E, Rodegher M, et al. Imaging patterns of gray and white matter abnormalities associated with PASAT and SDMT performance in relapsing-remitting multiple sclerosis. Mult Scler 2019;25:204-216.

31. Feys P, Moumdjian L, Van Halewyck F, et al. Effects of an individual 12-week community-located "start-to-run" program on physical capacity, walking, fatigue, cognitive function, brain volumes, and structures in persons with multiple sclerosis. Mult Scler 2019;25:92-103.

32. Vollmer T, Huynh L, Kelley C, et al. Relationship between brain volume loss and cognitive outcomes among patients with multiple sclerosis: a systematic literature review. Neurol Sci 2016;37:165-179.

33. Benedict RH, Cohan S, Lynch SG, et al. Improved cognitive outcomes in patients with relapsing-remitting multiple sclerosis treated with daclizumab beta: results from the DECIDE study. Mult Scler 2018;24:795-804.

34. Johnen A, Landmeyer NC, Burkner PC, Wiendl H, Meuth SG, Holling H. Distinct cognitive impairments in different disease courses of multiple sclerosis: a systematic review and meta-analysis. Neurosci Biobehav Rev 2017;83:568-578.

35. Weinstock-Guttman B, Galetta SL, Giovannoni G, et al. Additional efficacy endpoints from pivotal natalizumab trials in relapsing-remitting MS. J Neurol 2012;259: 898-905.

36. Tombaugh TN. A comprehensive review of the Paced Auditory Serial Addition Test (PASAT). Arch Clin Neuropsychol 2006;21:53-76.

37. Barker-Collo SL. Within session practice effects on the PASAT in clients with multiple sclerosis. Arch Clin Neuropsychol 2005;20:145-152.

38. Sonder JM, Burggraaff J, Knol DL, Polman CH, Uitdehaag BM. Comparing long-term results of PASAT and SDMT scores in relation to neuropsychological testing in multiple sclerosis. Mult Scler 2014;20:481-488

39. Morrow SA, Drake A, Zivadinov R, Munschauer F, Weinstock-Guttman B, Benedict RH. Predicting loss of employment over three years in multiple sclerosis: clinically meaningful cognitive decline. Clin Neuropsychol 2010;24:1131-1145.

40. Benedict RH, Morrow S, Rodgers J, et al. Characterizing cognitive function during relapse in multiple sclerosis. Mult Scler 2014;20:1745-1752.

41. Morrow SA, Jurgensen S, Forrestal F, Munchauer FE, Benedict RH. Effects of acute relapses on neuropsychological status in multiple sclerosis patients. J Neurol 2011; 258:1603-1608.

42. Pardini M, Uccelli A, Grafman J, Yaldizli O, Mancardi G, Roccatagliata L. Isolated cognitive relapses in multiple sclerosis. J Neurol Neurosurg Psychiatry 2014;85: 1035-1037.
43. LaRocca NG, Hudson LD, Rudick R, et al. The MSOAC approach to developing performance outcomes to measure and monitor multiple sclerosis disability. Mult Scler 2018;24:1469-1484.

44. Ontaneda D, LaRocca N, Coetzee T, Rudick R; NMSS MSFC Task Force. Revisiting the multiple sclerosis functional composite: proceedings from the National Multiple Sclerosis Society (NMSS) Task Force on Clinical Disability Measures. Mult Scler 2012;18:1074-1080.

45. Cohen JA, Reingold SC, Polman CH. Disability outcome measures in multiple sclerosis clinical trials: current status and future prospects. Lancet 2012;11:467-476.

46. Goldman MD, LaRocca NG, Rudick RA, et al. Evaluation of multiple sclerosis disability outcome measures using pooled clinical trial data. Neurology 2019;93:e1-e11.

47. Fuchs TA, Benedict RHB, Bartnik A, et al. Preserved network functional connectivity underlies cognitive reserve in multiple sclerosis. Hum Brain Mapp 2019;40: 5231-5241.

48. Hundehege P, Cerina M, Eichler S, et al. The next-generation sphingosine-1 receptor modulator BAF312 (siponimod) improves cortical network functionality in focal autoimmune encephalomyelitis. Neural Regen Res 2019;14:1950-1960.

49. Arnold DA, Fox R, Bar-Or A, et al. Effect of siponimod on cortical grey matter and thalamic volume in patients with secondary progressive multiple sclerosis: results of the EXPAND study. Poster presented at the 35th Congress of the European Committee for Treatment and Research in Multiple Sclerosis; September 11-13, 2019, Stockholm, Sweden P382 2019.

50. Bisecco A, Rocca MA, Pagani E, et al. Connectivity-based parcellation of the thalamus in multiple sclerosis and its implications for cognitive impairment: a multicenter study. Hum Brain Mapp 2015;36:2809-2825.

51. Houtchens MK, Benedict RHB, Killiany R, et al. Thalamic atrophy and cognition in multiple sclerosis. Neurology 2007;69:113-123.

52. Bergsland N, Zivadinov R, Dwyer MG, Weinstock-Guttman B, Benedict RH. Localized atrophy of the thalamus and slowed cognitive processing speed in MS patients. Mult Scler 2016;22:1327-1336.

53. Benedict RH, Krupp L, Francis G, Rao S, LaRocca N, Langdon DW; Group MCW. NINDS Common Data Elements, Multiple Sclerosis, Neuropsychology/Cognition Recommendations. Washington, DC: National Institute for Neurological Diseases and Stroke; 2012.

54. Benedict RH, Fischer JS, Archibald CJ, et al. Minimal neuropsychological assessment of MS patients: a consensus approach. Clin Neuropsychol 2002;16:381-397.

55. Parmenter BA, Testa SM, Schretlen DJ, Weinstock-Guttman B, Benedict RH. The utility of regression-based norms in interpreting the Minimal Assessment of Cognitive Function in Multiple Sclerosis (MACFIMS). J Int Neuropsychol Soc 2010;16:6-16

56. Fischer JS, Priore RL, Jacobs LD, et al. Neuropsychological effects of interferon beta1a in relapsing multiple sclerosis: Multiple Sclerosis Collaborative Research Group. Ann Neurol 2000;48:885-892.

57. Silva PHR, Spedo CT, Baldassarini CR, et al. Brain functional and effective connectivity underlying the information processing speed assessed by the Symbol Digit Modalities Test. Neuroimage 2019;184:761-770.

58. Kapoor R, Ho PR, Campbell N, et al. Effect of natalizumab on disease progression in secondary progressive multiple sclerosis (ASCEND): a phase 3, randomised, doubleblind, placebo-controlled trial with an open-label extension. Lancet Neurol 2018;17: 405-415.

59. Hauser SL, Bar-Or A, Comi G, et al. Ocrelizumab versus interferon beta-1a in relapsing multiple sclerosis. N Engl J Med 2017;376:221-234.

60. Sumowski JF, Chiaravalloti N, Wylie G, et al. Cognitive reserve moderates the negative effect of brain atrophy on cognitive efficiency in multiple sclerosis. J Int Neuropsychol Soc 2009; 15:606-612.

61. Patel VP, Feinstein A. The link between depression and performance on the symbol digit Modalities test: mechanisms and clinical significance. Mult Scler 2019;25: 118-121. 


\section{Neurology}

\section{Siponimod and Cognition in Secondary Progressive Multiple Sclerosis: EXPAND Secondary Analyses \\ Ralph H.B. Benedict, Davorka Tomic, Bruce A. Cree, et al.}

Neurology 2021;96;e376-e386 Published Online before print December 16, 2020

DOI 10.1212/WNL.0000000000011275

\section{This information is current as of December 16, 2020}

\section{Updated Information \& Services}

References

Citations

Subspecialty Collections

Permissions \& Licensing

Reprints including high resolution figures, can be found at: http://n.neurology.org/content/96/3/e376.full

This article cites 56 articles, 4 of which you can access for free at: http://n.neurology.org/content/96/3/e376.full\#ref-list-1

This article has been cited by 1 HighWire-hosted articles: http://n.neurology.org/content/96/3/e376.full\#\#otherarticles

This article, along with others on similar topics, appears in the following collection(s):

\section{All Clinical trials}

http://n.neurology.org/cgi/collection/all_clinical_trials

Multiple sclerosis

http://n.neurology.org/cgi/collection/multiple_sclerosis

Neuropsychological assessment

http://n.neurology.org/cgi/collection/neuropsychological_assessment

Information about reproducing this article in parts (figures,tables) or in its entirety can be found online at:

http://www.neurology.org/about/about_the_journal\#permissions

Information about ordering reprints can be found online:

http://n.neurology.org/subscribers/advertise

Neurology ${ }^{\circledR}$ is the official journal of the American Academy of Neurology. Published continuously since 1951, it is now a weekly with 48 issues per year. Copyright (O) 2020 American Academy of Neurology. All rights reserved. Print ISSN: 0028-3878. Online ISSN: 1526-632X.

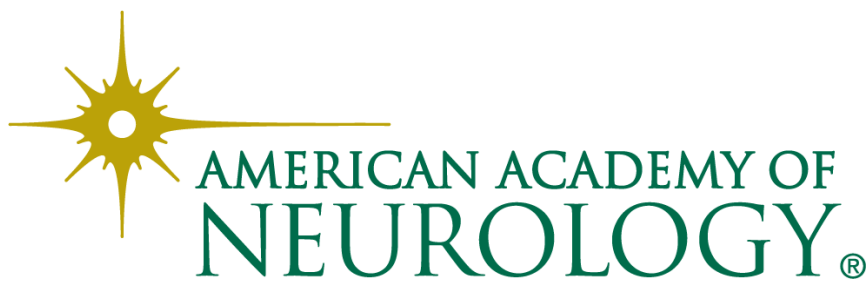

